\title{
Semente a Semear: o teatro germinando mudanças em uma comunidade.
}

Valdeci Moreira de Souza ${ }^{1}$ - PROFARTES-UnB Orientadora: Clarice da Silva Costa ${ }^{2}$ - PROFARTES-UnB

Resumo: Esse artigo apresenta os conceitos e os objetivos que permeiam a metodologia de ensino de teatro do Espaço Semente, na cidade do Gama, Região Administrativa do Distrito Federal, e também sua trajetória como ambiente gratuito de exercício de arte. A partir de um olhar teórico do Teatro da comunidade e das problemáticas envolvidas na condição de Periferia, o presente artigo traz uma parte da pesquisa da dissertação de mestrado que investiga o trabalho da Semente Companhia de Teatro, uma amostra do que a arte pode modificar na vida de atores e não atores na periferia de Brasília.

Palavras-chave: teatro comunitário; periferia; Espaço Semente; Macunaíma.

\section{Introdução}

Mundialmente, a divisão entre centros e periferias adquire diversas configurações, variando de acordo com o tempo, o espaço e as características de cada sociedade. No caso do Brasil, a relação Centro-Periferia apresenta-se de forma perversa, pois limites quase intransponível, bem como validados culturalmente. Essa relação está prioritariamente centrada no poder econômico de classe, no acesso à informação e a bens simbólicos como a arte, na intensidade da vida cívica (DOMINGUES, 1994) e nos desdobramentos de situações históricas próprias do processo de formação do país, como a escravidão de pessoas negras (GOMES, 1990).

Visto que há uma grande desigualdade política, social e econômica entre os habitantes do centro e os da periferia, gera-se efeitos sobre a real garantia de direitos e sobre o acesso que os indivíduos têm a serviços e bens importantes para sua sobrevivência digna e seu bem-estar. Sendo assim, o exercício da cidadania plena e, portanto, da ativa participação nas decisões da sociedade - o ideal pressuposto da nossa democracia, na qual "todo poder

1 Valdeci Moreira de Souza é professor da rede pública do Distrito Federal, atuando na área administrativa do Gama, mestrando do PPGPROFARTES-UnB. Email:

2 Clarice da Silva Costa é professora da Universidade Federal de Goiás e credenciada no PPGPROFARTES-UnB. Email: 
emana do povo" (Constituição Federal Brasileira, 1988) -, fica comprometido para aquelas pessoas que não compõe a elite.

É nesse ponto de vista sobre a realidade da nossa sociedade que o teatro comunitário feito de forma engajada poderia ganhar um papel transformador do exercício da cidadania e na inclusão sociocultural, e, por conseguinte, fortalecedor das relações democráticas. Portanto, vale destacar 0 trabalho realizado pelo Espaço Semente ao longo de sua existência na comunidade do Gama, trabalhando no contexto desta periferia, e com os problemas de seus indivíduos como principal foco para ação através da arte.

Atualmente, a Cia Semente de Teatro, através da minha pessoa enquanto diretor, direcionou sua ação para os sujeitos da periferia na montagem do espetáculo Macunaíma, baseado na obra homônima do escritor Mário de Andrade, a fim de investigar essa problemática. O trabalho vem sendo realizado com não atores na maioria e também com atores convidados, desde o início de 2016 e teve sua estreia em novembro de 2017.

\section{A Periferia e a Cidadania - O papel do teatro comunitário nessa problemática}

A periferia, como é o caso da região administrativa do Gama, DF, é aquilo que separada do centro urbano, envolve-o, sendo este conceito muitas vezes usado de forma negativa e relativizada, como afirma Domingues (1994), "em contraposição a um centro". Seus habitantes sofrem com o isolamento acarretado pelas estruturas segregacionistas da sua sociedade, sendo este isolamento o fator gerador da condição periférica:

É o grau de afastamento a um centro que clarifica a posição periférica (física, social, morfológica etc.) [...]. Enquanto agregado social, a periferia define-se, por isso e também, não pela densidade ou pela intensidade do inter-relacionamento interno ao nível local, mas sim pela dependência, pela subalternidade face às áreas centrais aos locais de destino dos habitantes-pendulares. (DOMINGUES, 1994).

A periferia ou o subúrbio, que é quando esta configuração de afastamento atinge proporções de metrópole ou megalópole, configura-se como espaço de exclusão das pessoas que não podem exercer sua cidadania, não têm o devido acesso a serviços públicos essenciais, como saúde, escolas, áreas de lazer e segurança pública. (DOMINGUES, 1994) 
É importante ressaltar, como afirma Silva (2015), que ao se discutir a relação centro-periferia e a construção desses conceitos, deve-se ter em mente as desigualdades sociais, conflitos e transformações ocorridas no mundo, principalmente a partir do advento da modernidade. Portanto para a compreender essa dinâmica se faz necessária uma visão processual e histórica da realidade, na qual se evidencia a presença das relações de classe e da dinâmica do capitalismo desde os primórdios como um relevante fator, dentre outros como etnia e religião, para essa separação, pois estabelece o consumo e a posse como medidas de status social e de poder.

Paula \& Paula (2011) inferem outro aspecto importante para a discussão atual da relação entre os centros e as periferias, os quais deixaram de ser isoladas por grandes distâncias físicas e passam a ser diferenciados por "distâncias culturais":

Centro e periferia não necessariamente correspondem a lugares físicos/geográficos próximos ou distantes das regiões de maior possibilidade de acesso a bens e serviços proporcionados pelo sistema, mas espaços de inclusão, integração, exclusão, segregação que se entrecruzam e interpenetram geográfica, cultural, política e socialmente, guardando, para si, suas condições e especificidades. (PAULA \& PAULA 2011).

Desta forma, o universo das relações sociais entre o periférico e o central compõe-se de formas diferentes de expressões linguísticas, artísticas, morais e políticas. E que se diferem inevitavelmente no tipo de conteúdo cultural e simbólico que é produzido e acessível para cada setor, mas ainda marcadamente centralizados à força de acordo com os padrões dos dominantes. O subúrbio passa a não se limitar somente a distância física do centro, mas a uma "distância sociológica" (DOMINGUES, 1994) grandemente relacionada ao déficit educacional, econômico e de cidadania.

Vale discutir o que Milton Santos (1991) acrescenta sobre o assunto ao tratar de mudanças na sociedade no geral decorrentes da globalização e do avanço tecnológico e informacional. Para ele, a contemporaneidade fez surgir um fenômeno que potencializou a capacidade de imposição da metrópole sobre a periferia. Há, segundo o autor, uma dissolução do tempo de comunicação entre o centro e seu entorno que universaliza a metrópole que emite as informações/cultura que todos consomem. Agravando a distância sociológica entre o centro e o que o circunda, criando um tempo 
"demultiplicado", um tempo que acontece no âmbito social e por isso é classificatório e segregador: Em cada outro ponto [...] da rede urbana ou do espaço, temos tempos subalternos e diferenciados, marcados por dominâncias específicas (SANTOS, 1991). Pode-se afirmar que gradativamente um tipo de exclusão que não só proíbe o cidadão periférico de circular pelo centro e deste usufruir, mas o proíbe de usufruir de seu próprio espaço e de sua cultura a partir de uma recombinação dos aspectos da realidade urbana, cultural, e econômica da atualidade.

Ao falar de cidadania, Milton Santos (1987) reconhece que a questão territorial atravessa a possiblidade de usufruir dos direitos civis e sociais que em tese deveriam ser garantidos igualmente para cada pessoa.

O valor do indivíduo depende, em larga escala, do lugar onde está[...]. Em nosso país, o acesso aos bens e serviços essenciais, públicos e até mesmo privados é tão diferencial e contrastante, que uma grande maioria de brasileiros, no campo e na cidade, acaba por ser privada desses bens e serviços. Às vezes, tais bens e serviços simplesmente não existem na área, às vezes não podem ser alcançados por questão de tempo ou de dinheiro." (SANTOS, 1987)

O autor ainda atribui grande parte do problema e da condição de excluída da população mais pobre à atuação do Estado. Este é negligente à situação, principalmente porque para as pessoas que o compõem a redução de desigualdades e injustiças não é de interesse. O Estado, segundo ele, contribui para a diferenciação dos espaços, periféricos e centrais, garante sempre a segurança, a limpeza pública, a valorização dos empreendimentos, a conservação da infraestrutura etc. ao centro rico e cria dificuldades inúmeras para as demais regiões

Neste contexto, é importante o papel que o exercício de um teatro comunitário na periferia teria. Este se configuraria como uma forma específica de desenvolvimento cultural local, pois possibilitaria a quem participasse de seus processos apreender aspectos das expressões artísticas sofisticadas do centro ao mesmo tempo em que constitui novas formas de representação subjetiva da realidade e do seu meio.

As práticas do teatro feito na comunidade, para a comunidade, servem a um mesmo propósito apesar da confusão das nomenclaturas, como explica Benza (2013): 
De acordo com o espaço onde se desenvolvem e os objetivos, podem receber nomes diversos tais como teatro aplicado, drama aplicado, teatro em comunidade, teatro educação, teatro para o desenvolvimento, teatro popular, entre outros.

O teatro feito na comunidade, em resumo, dá oportunidade de acesso a conhecimento e cultura que antes essas pessoas não tinham como obter (TELLES, 2003 p.66) e permite acima de tudo um processo de criação autêntico que leva em consideração a realidade da vida delas e toda a problemática envolvida no ser periférico e no estar na periferia, em um processo criativo e reflexivo com e para o seu mundo. Sobre o teatro comunitário, Sanches (2014) acrescenta:

[as experiências do teatro em comunidade] promovem a construção de novos sujeitos políticos, nas quais sobrevoam questionamentos ao ordenamento social vigente e à configuração de novos modos de sociabilidade e participação coletiva erigidos sobre os valores da solidariedade da construção conjunta. Incluem a ideia de potencializar a autonomia, assentada na criação de territórios onde os coletivos vão construindo seu novo mundo. (SANCHES, 2014 p.3).

O teatro que antes era monopolizado pelas classes dominantes, torna-se democratizado e então mais próximo dos cidadãos excluídos (TELLES, 2003 p.66). Sua função dominadora das massas, que é também compartilhada com todas as artes ditas eruditas, pode ser então revertida e ele passa a ser usado como um instrumento de reflexão que visa dotar os sujeitos com as armas da própria liberação intelectual.

Procura-se assim, transformar o aluno em um protagonista da ação dramática que representa situações ligadas a sua própria vida (TELLES, 2003 p.68), e possibilita que ele perceba e, a partir daí, modifique as nuances da subjugação que sofre em sua sociedade.

Desta forma, o teatro comunitário garante uma implicação naquilo que se faz e naquilo que se assiste que é motor para a reinterpretação do mundo em que se vive e em como se vive neste mundo, vinculando-se necessariamente à realidade. Em seus métodos, o teatro possibilita vislumbrar como as relações sociais se estruturam e como as opressões operam nas esferas individuais e na comunidade como um todo.

Existem trabalhos teatrais que não procuram gerar só um prazer ou uma vivência estética, mas sim utilizar distintas ferramentas e possibilidades que a prática teatral oferece para gerar um impacto na vida das pessoas e procurar construir 
uma sociedade melhor. Estes trabalhos geralmente consistem em oficinas de teatro, realizadas fora do espaço tradicional teatral, onde se procura usar os conhecimentos da área para gerar benefício às pessoas. Nestas oficinas, de modo geral, o mais importante é o processo experimentado pelos envolvidos e as modificações que o trabalho com o teatro possa gera em suas vidas. (BENZA, 2013).

Sobretudo, o teatro em comunidade faz com que os indivíduos que nele interagem, principalmente como atores, assumam papel de protagonistas em seus problemas, mas mesmo que não, ainda cientes de suas implicações e possíveis causas.

O trabalho artístico, o próprio feito de "atuar", implica pôr o corpo em uma situação distinta do cotidiano, portanto a atuação permite explorar além dos limites. [...] Este é o primeiro passo na confirmação de sujeitos ativos que tomam consciência que podem agir em seu entorno, sujeitos que não se resignam a aceitar o que vem como dado." (SANCHES, 2014).

A cidadania, então, pensada como acesso a direitos e como a possibilidade de agir a partir deles é objetivo dessa forma de se fazer arte. Neste sentido, o teatro cria, em um esforço comunitário, meios para que esse indivíduo tome consciência de si e do mundo. E a partir do senso crítico que o processo de fazer uma arte genuína lhe proporciona, permite que ele se volte contra as barreiras físicas e psicológicas que o aprisionam.

Portanto, compreende-se que o Teatro pode acarretar grandes mudanças na experiência individual das pessoas e em sua vida em sociedade como parte ativa dela. É nisso que o Espaço Semente se ampara para o desenvolvimento de seus trabalhos junto à comunidade do Gama, e das demais regiões periféricas de Brasília.

Por meio de sua metodologia de ensino de teatro, o Espaço Semente visa abarcar uma visão geral do aluno que participa das oficinas e atividades, ou seja, seu contexto social, econômico, cultural etc. Porque assim pretende entender todas as possíveis nuances que evidenciem os conflitos que esse sujeito apresente quanto a sua condição de cidadão periférico e trabalhá-las junto a ele.

\section{Espaço Semente - os objetivos de se fazer teatro no Gama}


O Espaço Semente é caracterizado por e dirigido à relação íntima com a realidade periférica. Foi criado na Região Administrativa do Gama em 2007 e nela exerce suas atividades ainda hoje. Seu corpo de participantes bem como espectadores são principalmente de regiões administrativas pobres do Distrito Federal e entorno do DF. Sendo assim, pode-se dizer que o teatro desenvolvido pelo Espaço Semente é desenvolvido pela, para, e com a periferia.

O Gama, distante 30 quilômetros de Brasília e dos centros culturais abastados da capital, tem uma população aproximada de 140 mil habitantes. Fundada em 1966, para abrigar moradores realojados de áreas ocupadas durante a construção de Brasília, como a Vila Planalto e a Vila Amauri, só foi transformada em Região Administrativa em 1989.

Hoje, o Gama é carente de possibilidades de lazer, cultura e arte e os cidadãos tem que recorrer a outras regiões do Distrito Federal e até do Entorno. A RA vem passando por um processo discreto de lento abandono dos espaços culturais ao longo do tempo principalmente a partir da década de 1990, como foi o caso do Centro Cultural Cine Itapuã um dos espaços culturais mais conhecidos da cidade e o segundo cinema a ser inaugurado no DF que se encontra desativado desde 2005 (CAMELO, 2011), e o estabelecimento da Região Administrativa como uma cidade dormitório. Vale citar, entretanto, o Estádio Walmir Campelo Bezzerra, mais conhecido como Bezerrão, que também movimenta o cenário da cidade.

Sabendo disso, um dos objetivos do Espaço Semente é, através da educação artística e do incentivo pelo conhecimento, pelo engajamento político (mas não partidário) e pela solidariedade que são praticados ao longo de cada processo de montagem de espetáculo, oferecer oportunidades de expansão de conhecimento e cultura para os moradores dessa periferia, que não conta com muitas possibilidades. Vale citar uma grande iniciativa que se deu desde o começo do projeto, com o estabelecimento de uma biblioteca pública, mediante a necessidade observada nos cidadãos do Gama de conhecimento de qualidade. Na antiga sede do Espaço, no subsolo de uma loja, qualquer pessoa poderia levar um livro para ler com o simples compromisso de que o devolveria. Inspirado principalmente pelas filosofias da pedagogia de Paulo Freire e também pelo Teatro do Oprimido de Augusto Boal, que são aplicadas aos métodos do ensino e das oficinas de teatro. O Espaço Semente concede ao 
indivíduo a oportunidade de renovar-se e de integrar-se à sociedade em que vive tanto no contexto local, o Gama, quanto em um contexto geral, mais macroscópico, na realidade por ele percebida que se insere o país.

A Semente Cia de Teatro pretende despertar um processo de transformação no indivíduo para que ele possa assumir o caráter de sujeito ativo, mais do que um ator que simplesmente emule um texto em seu corpo e voz. Visando que este não só receba e reproduza conhecimento, como lhe é ensinado a fazer em toda sua educação formal, mas o crie e o utilize para pensar soluções aos problemas de sua comunidade local, de sua sociedade como um todo e de sua vida pessoal.

A prática do teatro no Espaço Semente inclui o habitante da periferia, aquele separado por uma distância cultural do centro (PAULA \& PAULA, 2011), tanto do Gama quanto do entorno, em projetos que propiciem crescimento pessoal e cultural. Oferece, acima de tudo, uma oportunidade de aprender e de se transformar com a atuação e com as suas questões pessoais que são levantadas como obstáculos e como potencialidades para esse indivíduo. Por isso conhecer o aluno se mostra essencial, para que se possa trabalhar com ele essas problemáticas.

No Espaço Semente o aluno participante das oficinas é cobrado e incentivado constantemente a pesquisar o que está fazendo, a propor cenas etc. É dever do ator saber sobre seu personagem, sobre a obra e executar seu papel zelando pela qualidade de sua interpretação, porém dentro do seu limite enquanto ator iniciante, não profissional. Em resumo, ele é estimulado a aprender e a se aperfeiçoar e é acolhido frente às suas dificuldades pessoais.

Além das questões pedagógicas, é primordial que 0 indivíduo desenvolva pensamentos e atitudes críticas que lhe servirão em todos os momentos da vida através dos conhecimentos adquiridos da prática (e da reflexão) teatral. Ele deve ser capaz de conhecer sua realidade e de se autoconhecer.

Espera-se que o aluno saia emancipado, ainda que só intelectualmente, dos poderes opressores do governo e da mídia, que distorcem a realidade de maneira a aumentar sua exclusão e paralisar seus mecanismos de revolta e indignação. Durante o processo teatral o aluno adquire os instrumentos e a vontade de exercer sua cidadania plenamente, levando em conta as dificuldades que enfrenta na periferia. 
Pelo amadurecimento crítico provocado pelo contato com o teatro, o indivíduo torna-se consciente de sua realidade e adquire a capacidade de exigir seus direitos sociais e políticos que deveriam ser garantidos pelo Estado, utilizando a arte e todo o desenvolvimento que adquiriu ciente de seu valor enquanto ser humano e cidadão, de suas responsabilidades e de suas possibilidades.

A Semente Cia de Teatro pretendeu, com a montagem do espetáculo Macunaíma, criar uma oportunidade de desenvolvimento pessoal e intelectual para aqueles envolvidos, possibilitando que através do estudo e da prática teatral esses indivíduos possam dar novos sentidos para a realidade que vivem. O processo do espetáculo em discussão se iniciou ainda em 2016, com o oferecimento de oficinas de teatro gratuitas para atores e não atores que se dirigissem ao Espaço Semente e estreou no mês de novembro do ano seguinte, 2017.

A proposta pedagógica de Macunaíma visou englobar todos os aspectos benéficos do fazer teatral, e mais especificamente do teatro em comunidade. $O$ processo que aconteceu no Espaço Semente se desdobrou para além de seus limites físicos, pois causou modificações profundas naquelas pessoas que dele fazem parte. A reflexão e a percepção da realidade desencadeadas pelo exercício dramático da obra de Mário de Andrade causaram efeitos significativos que advieram não da atuação simples e pura, mas sim de um meio diferente de se pensar o aluno, suas experiências e suas individualidades na criação de um tipo de arte, que por isso e com isso, torna-se especialmente pessoal ao mesmo tempo em que é grupal.

\section{Considerações finais}

Portanto, conclui-se a importância do teatro na busca por uma cidadania sem barreiras econômicas ou geográficas, incluindo o indivíduo da periferia nos processos político-sociais que regem sua convivência em sociedade. A arte dramática em comunidade tem o poder de conscientizar o indivíduo sobre sua própria condição, bem como as causas desta, e sobre suas responsabilidades enquanto pessoa em um país dito democrático, mas que funciona na realidade com base em outros valores, que provocam a desigualdade. Sendo assim, o processo pretende também fazer com que o ator amador nele envolvido assuma papel ativo em sua jornada acadêmica, profissional ou artística, 
contornando as dificuldades a eles impostas por sua condição de desprivilegiado socialmente.

O Espaço Semente esperançoso no papel da arte na sociedade brasileira contemporânea investe neste trabalho, pois acredita transformará para melhor a existência das pessoas. A peça Macunaíma, atual trabalho da Companhia, bem como diversos espetáculo já montados são um modo de incluir e empoderar o cidadão da periferia em algo que propicie seu crescimento intelectual, social e cultural e o despertar um senso crítico que the servirá em todos os momentos da sua vida como ferramenta para lutar e conquistar sua cidadania, seu lugar de direito na sociedade.

\section{Referências}

BRASIL. Constituição (1988). Constituição da República Federativa do Brasil. Brasília, DF, Senado, 1998.

\section{Artigos de Periódicos}

DALL'ORTO, Felipe Campo. O teatro do oprimido na formação da cidadania. Fênix - Revista de História e Estudos Culturais. Vol. 5, ano V, $n^{\circ} .2$, 2008

DOMINGUES, Álvaro. (Sub)úrbios e (sub)urbanos o mal-estar da periferia ou a mistificação de conceitos? Revista da Faculdade de Letras - Geografia. Porto. Vol X/XI, 1994. pp 5-18.

GOMES, Marco A. A. F.. Escravismo e cidadania: notas sobre a ocupação da periferia de Salvador no século XIX. Revista de Urbanismo Arquitetura. UFBA. 1990. pp. 9-19.

BENZA, Rodrigo. Realidade e Ficção nas Oficinas de Teatro: Construindo questionamentos e alternativas. Cena em Movimento, n 3, UFRGS. 2013

NOGUEIRA, M. P. Tentando definir o Teatro na Comunidade. In: Anais da IV Reunião Científica de Pesquisa e Pós-Graduação em Artes Cênicas; 2007. Belo Horizonte. Disponível em: http://www. portalabrace.org

PAULA, Luciene de; PAULA, Sandra Leila de. No centro da periferia, a periferia no centro. IPOTESI, JUIZ DE FORA, v.15, n.2 - Especial, p. 107-121, jul./dez. 2011

SILVA, J. C. L. T. B. Centro e periferia na contemporaneidade: o continuísmo do discurso da desigualdade social. UFMA São Luís. Jornada Internacional de Políticas Públicas. Anais da VII Jornada Internacional de Políticas Públicas: Para além da crise global: experiências e antecipações concretas. 2015 
TELLES, Narciso. Teatro Comunitário: ensino de Teatro e Cidadania. Universidade federal de Uberlândia. 2003.

\section{Sites e artigos disponíveis online}

CAMELO, Emanuelle Santos. A importância do resgate da memória cultural no processo de ensino-aprendizagem. 2011. Disponível em:< https://repositorio.ucb.br/jspui/handle/123456789/9258>. Acesso em: 01/01/2018.

GDF, Administração Regional do Gama. Conheça a RA. Disponível em:< http://www.gama.df.gov.br/category/sobre-a-ra/conheca-a-ra/>. Acesso em: 22/08/2017.

SANCHES, R. Salina. Teatro comunitario y transformación social: La práctica artística en el proceso de construcción de una hegemonía alternativa. VIII Jornadas de Sociología de la UNLP, 3 al 5 de diciembre de 2014, Ensenada, Argentina. En Memoria Académica. Disponível em: <http://www.memoria.fahce.unlp.edu.ar/trab_eventos/ev.4219/ev.4219.pdf>.

SANTOS, Milton. O espaço do cidadão. Editora Nobel. São Paulo. 1987.

SANTOS, Milton. A Revolução Tecnológica e o Território: realidades e perspectivas. Terra Livre. São Paulo. n 9, pp. 7-17.1991

SOUZA, Gustavo. Culturas brasileiras periféricas no cenário brasileiro: funk, hip-hop e samba. 2006. Disponível em:< http://www.cult.ufba.br/enecul2006/gustavo_souza.pdf>. Acesso em 01/01/2018. 